\title{
Field and mesocosm trials on passive sampling for the study of adsorption and desorption behaviour of lipophilic toxins with a focus on OA and DTX1
}

\author{
Elie Fux ${ }^{a, b, ~}{ }^{*}$, Claire Marcaillou ${ }^{c}$, Florence Mondeguer $^{c}$, Ronel Bire $^{\mathrm{a}}$ and Philipp Hess ${ }^{\mathrm{a}}$ \\ ${ }^{a}$ Marine Institute, Biotoxin Chemistry, Rinville, Oranmore Co. Galway, Ireland \\ b Dublin Institute of Technology, School of Chemistry and Pharmaceutical Sciences, Kevin Street, Dublin 8, \\ ${ }^{c}$ IFREMER, Rue de l'ile d'Yeu, 44311 Nantes, France \\ *: Corresponding author : E. Fux, Tel.: +353 91387 382, email address : elie.fux@marine.ie
} Ireland

\begin{abstract}
:
It has been demonstrated that polymeric resins can be used as receiving phase in passive samplers designed for the detection of lipophilic marine toxins at sea and was referred to as solid phase adsorption toxin tracking (SPATT). The present study describes the uptake and desorption behaviour of the lipophilic marine toxins okadaic acid (OA) and dinophysistoxin-1 (DTX1) from Prorocentrum lima cultures by five styrene-divinylbenzene based polymeric resins Sepabeads ${ }^{\circledR}$ SP850, Sepabeads ${ }^{\circledR}$ SP825L, Amberlite ${ }^{\circledR}$ XAD4, Dowex ${ }^{\circledR}$ Optipore ${ }^{\circledR}$ L-493 and Diaion ${ }^{\circledR}$ HP-20. All resins accumulated OA and DTX1 from the $P$. lima culture with differences in adsorption rate and equilibrium rate. Following statistical evaluation, HP-20, SP850 and SP825L demonstrated similar adsorption rates. However, possibly due to its larger pore size, the HP-20 did not seem to reach equilibrium within $72 \mathrm{~h}$ exposure as opposed to the SP850 and SP825L. This was confirmed when the resins were immersed at sea for 1 week on the West Coast of Ireland. Furthermore, this work also presents a simple and efficient extraction method suitable to SPATT samplers exposed to artificial or natural culture media.
\end{abstract}

Keywords: Prorocentrum lima; SPATT; Okadaic acid; Dinophysistoxin-1; Polymeric resin 


\section{Introduction}

Due to their filter feeding nature, bivalve shellfish can accumulate toxins produced by naturally occurring planktonic algae to levels that are sometimes sufficient to induce shellfish poisoning in consumers. Several illnesses are associated with shellfish poisoning, in particular diarrhetic shellfish poisoning (DSP) caused by Okadaic acid (OA) and Dinophysistoxins (DTXs) is a widely observed syndrome around the world.

The recent development of passive samplers, referred to as solid phase adsorption toxin tracking (SPATT) for the detection of lipophilic marine toxins, offers a new tool to researchers to study lipophilic phycotoxins (MacKenzie et al., 2004). The use of passive samplers could be very useful in toxin distribution studies due to their ability to accumulate toxins onto the receiving phase in-situ, without need of energy and most importantly, avoiding bio-transformation occurring in living organisms. Beyond the wide range of applications that SPATT could offer to research purposes, their use in toxin monitoring programs could also be beneficial. Indeed, passive samplers have the advantage of providing a spatially and temporally integrated response, thereby reducing the number of analyses for long time monitoring.

The SPATT bags described by MacKenzie et al. (2004) consist of sachets made of $95 \mu \mathrm{m}$ mesh that contain the Diaion ${ }^{\circledR}$ HP-20 resin, a styrene diviniylbenzenze (DVB) copolymer. MacKenzie et al. found that, out of three different structure-based polymeric resins i.e. brominated styrene-divinylbenzene resin, acrylic-type polymer and styrene divinyl benzene copolymer, the latter was found to be the most suited receiving phase for SPATT bags (MacKenzie et al., 2004). This type of macroreticular polymer is widely used for water treatment applications such as removal of phenolic compounds ( $\mathrm{Li}$ et al., 2002), pesticides (Kyriakopoulos et al., 2005), salicylic acid (Otero et al., 2005) and phenylhydrazine derivatives (Zhai et al., 2003), as it offers a number of advantages over other adsorbents e.g. silica gels and alumina, such as ease of regeneration, high chemical stability and product availability for a wide range of pore sizes, densities and surface areas. These properties are expected to have a great influence on adsorption rate, equilibration rate and adsorbent capacities.

The potential use of the SPATT technology in monitoring programmes requires the development of a rapid and efficient method for toxin desorption from the receiving phase. The extraction method described by MacKenzie et al. (2004) is not practical for the extraction of large numbers of SPATTs as large volumes of methanol are required for the extraction and its subsequent evaporation is quite time consuming. Therefore, an alternative method for toxin desorption is required.

Conventional approaches of loading a known amount of analyte onto the adsorbent for extraction recoveries calculation was not applicable because of the chemical affinities of toxins for both methanol and the polymeric resin. Furthermore, spiking concentrated methanolic solutions of toxins into water for subsequent accumulation in an immersed SPATT disc was not successful and rapidly abandoned due to artefacts formation such as hydrolysis of pectenotoxin-2 (PTX2), and toxin adsorption on glassware (data not shown - Marine Institute). As a consequence, toxin accumulations on SPATT receiving phases were investigated by immersing the resins in cultures of Prorocentrum lima. $P$. lima is a well-known producer of OA and DTX1 as well as DTX4, a sulphated water soluble toxin (Hu et al., 1995) and several OA diol ester derivatives (Hu et al., 1992). $P$. lima cultures have been extensively studied and have the advantages of being robust and easy to cultivate. Therefore, the latter culture organism was chosen to load toxins on the SPATT for extraction method development as well as to compare the accumulation rate of OA and DTX1 in five types of styrene-DVB when used as receiving phases. In addition, several naturally contaminated SPATT discs were used for desorption method development and for resin comparison.

\section{Material and methods}

\subsection{Solvents and Reagents}

Acetonitrile $(A C N)$ used for liquid chromatography coupled to mass spectrometry (LC-MS) mobile phase in Ifremer and methanol were purchased as HPLC grade from Baker, Deventer, Holland. ACN used for LC-MS mobile phases in the Marine Institute was purchased as pestican grade from Labscan Ltd., Dublin, Ireland. Dichloromethane (DCM), hydrochloric acid $(\mathrm{HCl}, 37 \%)$ and sodium hydroxide $(\mathrm{NaOH})$ were obtained as analytical grade from Merck, Darmstadt Germany. The 95 $\mu$ m nylon mesh was purchased from John Staniar \& Co., Whitefield Manchester, UK. The embroidery hoops used to 
hold the mesh and the resin were purchased from Singer Sewing Centre, Galway, Ireland. The polymeric resins Diaion ${ }^{\circledR}$ HP-20, Sepabeads ${ }^{\circledR}$ SP850, Sepabeads ${ }^{\circledR}$ SP825L, Amberlite ${ }^{\circledR}$ XAD4 and Dowex $^{\circledR}$ Optipore $^{\circledR}$ L-493 were purchased from Sigma Aldrich, UK. Formic acid and ammonium formate were obtained from Sigma-Aldrich, UK (F-0507 and F-2004, respectively). Water was obtained from MilliQ water dispenser. Standards of OA and PTX2 were purchased as certified calibration solutions from the National Research Council (NRC), Halifax, Canada. Standards of Azaspiracid-1 (AZA1) were prepared from AZA1 isolated in 2001 in Tohoku University, Sandai Japan, from naturally contaminated mussels from the South West of Ireland (Hess et al., 2007).

\subsection{Polymeric resin properties and SPATTs preparation}

Five macroporous styrene-divinylbenzene copolymer resins were selected to evaluate a range of densities, pore sizes, pore volumes and surface areas (Table 1). Two types of SPATT designs were prepared: SPATT bags and SPATT discs. The SPATT bag design is well suited for studies in artificial media, as the bags can easily be inserted and retrieved from the carboys and culture flasks. The sachets were sewed in the nylon mesh and filled with resin $(3.00 \pm 0.05 \mathrm{~g})$. The resins were activated by immersing 30 sachets in methanol $(1 \mathrm{I})$ for $48 \mathrm{~h}$. The sachets were then immersed in water and sonicated a few minutes. Alternatively, experiments at sea were carried out using a SPATT disc design which is more robust, rapidly assembled and avoids sewing step. This design has been adapted from Sandvik and Rundberget - Norwegian Veterinary Institute (Personal communication, 2005). Portions of resins $(3.00 \pm 0.05 \mathrm{~g})$ were weighed and methanol $(100 \mathrm{ml})$ was subsequently added. Activation was performed by leaving the resins in contact with the methanol overnight, prior to a filtration on $95 \mu \mathrm{m}$ mesh $(\approx 21 \times 12 \mathrm{~mm})$.. The resin was wrapped with the mesh and clipped in an embroidery frame (diameter $8.8 \mathrm{~cm}$ ) allowing exposure on both sides of the frame. Methanol residues were removed by a 10 min sonication step in $500 \mathrm{ml}$ water. The SPATT discs were stored in MilliQ water at $4-6{ }^{\circ} \mathrm{C}$ until deployment.

\section{3. $P$. lima culture and resins exposure}

A mixed strain of $P$. lima (PL 4V and PL 2V) isolated in Galicia (Spain) was used to inoculate four batches in $10 \mathrm{I}$ experimental units each containing $6 \mathrm{I}$ of culture. This approach was chosen in order to have a sufficient quantity of inoculum and hence to reduce the time to obtain a large biomass. Both strains were grown in F/2 medium (Guillard and Ryther, 1962; Guillard, 1975) at 36 \%o salinity under $12 / 12$ light/dark cycle and exposed to $50 \mu \mathrm{E} \cdot \mathrm{m}^{-2} \cdot \mathrm{s}^{-1}$ irradiance at $16{ }^{\circ} \mathrm{C}$.

After 4 weeks of incubation the concentration reached $15000 \pm 3000$ cells $/ \mathrm{ml}(\mathrm{n}=4)$ determined on Nageotte counting chamber. Three 6 I batches were pooled together and allowed to grow for another 4 weeks while the remaining batch was lysed by the "freeze-thaw" method (Quilliam et al., 1996). After defrosting, the culture was sonicated for 10 minutes and dispensed in two 2 I experimental units containing 1.8 I of lysed culture. Five sachets, each containing one of the selected polymeric resins, were placed in each experimental unit for four days.

After 80 days of growth, the pooled culture media reached a density of $30000 \pm 2000 \mathrm{cells} / \mathrm{ml}(\mathrm{n}=3)$. Two culture aliquots $(100 \mathrm{ml}$ ) were passed through a GF/C filter (Whatman $1.2 \mu \mathrm{m}$ ). The cells were rinsed with distilled water to remove the salts and the wet residue was dried in an oven at $60{ }^{\circ} \mathrm{C}$ until constant weight was reached, resulting in dry residues of 16.1 and $17.3 \mathrm{mg}$. The pooled media (18 I) were homogenised for 30 minutes using magnetic stirring and $250 \mathrm{ml}$ aliquots were dispensed into 60 carboys while maintaining agitation. A $100 \mathrm{ml}$ sample was put aside and preserved in Lugol iodine for cell counts. One filled resin sachet was immersed in each carboy and was placed in the culture chamber until the end of the experiment. Carboys were shaken manually in the mornings and evenings. Three SPATT bags made of each resin were collected at 4 time points, 12, 24, 48 and $72 \mathrm{~h}$, and were kept at $6^{\circ} \mathrm{C}$ and extracted within $48 \mathrm{~h}$ of the exposure end.

\subsection{Toxin desorption from SPATT portions}

\subsubsection{Extraction method development}

The five resins that were immersed in one of the experimental media ( 1.8 I lysed culture) were used to determine the elution profile of OA and DTX1 using preparative chromatography equipment. In addition, a naturally contaminated SPATT disc that was placed at five meters depth in McSwynes Bay - Bruckless on the North West Coast of Ireland, for one week ending on the $15^{\text {th }}$ of November 2005, 
was also used for desorption profile determination as above. The resins contained in the sachets were rinsed twice in $500 \mathrm{ml}$ of MilliQ water to remove salts and vigorously shaken. A preparative chromatography system Shimadzu 10Avp (Kyoto, Japan) that includes a binary LC-8A Shimadzu pump and an automatic fraction collector Shimadzu FRC-10 was used for the determination of the toxin desorption profile. A preparative low pressure analytical glass column $(15.0 \times 1.0 \mathrm{~cm})$ was used to pack the polymeric resins $(3 \mathrm{~g})$. Methanol at $1 \mathrm{ml} / \mathrm{min}$ was used as mobile phase and $5 \mathrm{ml}$ fractions were collected over $60 \mathrm{~min}$. Each fraction was weighed for volume corrections and the extracts were transferred into LC vials and analysed by LC-MS on a Hybrid Quadrupole Time of Flight (Q-TOF) MS using an isocratic elution method.

\subsubsection{Extraction protocol for polymeric resins}

SPATTs were rinsed twice in $500 \mathrm{ml}$ of MilliQ water to remove salts and vigorously shaken. The contaminated resins were removed from the mesh and inserted into empty solid phase extraction (SPE) glass cartridges placed on a manifold. Vacuum was applied in order to remove the remaining water. A $23 \mathrm{ml}$ methanol portion was used to elute the resin at ca $1 \mathrm{ml} / \mathrm{min}$ flow rate. The extracts were transferred into $25 \mathrm{ml}$ volumetric flasks and an additional $2 \mathrm{ml}$ was used for rinsing and to complete up to the mark. Extract aliquots were taken from the volumetric flask, inserted into LC vials and injected in a LC-MS system.

\subsection{Determination of toxin contents of cultures}

The P.lima culture was homogenised slowly using a magnetic stirrer for one hour. The culture was constantly stirred, to avoid sedimentation of the cells, and 13 aliquots $(40 \mathrm{ml})$ were taken using a pipette and dispensed into polypropylene centrifuge tubes. One $40 \mathrm{ml}$ aliquot was put aside and preserved in Lugol iodine for cell counts under optical microscope.

Method A: Three solutions were placed in a water bath at $100{ }^{\circ} \mathrm{C}$ for 10 minutes, allowed to cool at room temperature and subsequently hydrolysed by adding $5 \mathrm{ml}$ of $2.5 \mathrm{M} \mathrm{NaOH}$ solution and placed for 20 minutes in a water bath at $76{ }^{\circ} \mathrm{C}$. The solutions were allowed to cool at room temperature and were neutralised by addition of $5 \mathrm{ml}$ of $2.5 \mathrm{M} \mathrm{HCl}$ solution. The hydrolysed solutions were partitioned by liquid/liquid extraction (LLE) using DCM $(40 \mathrm{ml})$; this was repeated three times. The DCM fractions were combined and evaporated to dryness using a speed vac at $50{ }^{\circ} \mathrm{C}$. The dry residue was resuspended in $5 \mathrm{ml}$ of methanol, filtered on $0.2 \mu \mathrm{m}$ filters and analysed by LC-MS.

Method B: Three solutions were placed in a water bath at $100^{\circ} \mathrm{C}$ for 10 minutes, allowed to cool at room temperature and subsequently partitioned using DCM $(40 \mathrm{ml})$; this was repeated three times. The DCM fractions were combined and evaporated to dryness using a speed vac at $50{ }^{\circ} \mathrm{C}$. The remaining aqueous phase was hydrolysed following the procedure described in method $A$. The hydrolysed solution was partitioned three times using DCM as described above. The dry residue obtained from the three portioning steps was reconstituted in $5 \mathrm{ml}$ methanol, filtered on $0.2 \mu \mathrm{m}$ cartridges and analysed by LC-MS.

Method C: Three solutions were placed in a water bath at $100{ }^{\circ} \mathrm{C}$ for 10 minutes, allowed to cool at room temperature and stored at $-20^{\circ} \mathrm{C}$. An additional three solutions were frozen at $-20^{\circ} \mathrm{C}$ without heat treatment. The six frozen samples were allowed to defrost at room temperature for 24 hours and placed in a sonicating bath containing ice for 10 minutes. The solutions were centrifuged at $3000 \mathrm{rpm}$ for 20 minutes at $0^{\circ} \mathrm{C}$ and extracted on C18 SPE cartridges (VWR; $500 \mathrm{mg} ; 3 \mathrm{ml}$ ). SPE conditions were optimised on yield, extraction efficiency and reproducibility from $P$. lima culture samples. The different steps of the SPE procedure consisted in drying and compressing the C18 stationary phase with nitrogen for $4 \mathrm{~min}$. The cartridge was then equilibrated with $100 \%$ methanol $(20 \mathrm{ml})$ and conditioned with water $(20 \mathrm{ml})$ at $8 \mathrm{ml} / \mathrm{min}$. The culture sample $(5 \mathrm{ml})$ was loaded on the SPE at 2.5 $\mathrm{ml} / \mathrm{min}$ and subsequently washed with water $(5 \mathrm{ml})$ at $3 \mathrm{ml} / \mathrm{min}$. Then, the toxins were eluted with 100 $\%$ methanol $(5 \mathrm{ml})$ at $3 \mathrm{ml} / \mathrm{min}$ and the stationary phase was dried with pulse air $(6 \mathrm{ml})$. The effluent $(5$ $\mathrm{ml}$ ) was evaporated to dryness using a speed vac. The dry residue was reconstituted in $100 \%$ methanol (1 ml) and inserted in a LC vial for LC-MS analysis using the LCQ ion trap MS. 


\subsection{Naturally contaminated SPATTs}

\subsubsection{Bruckless Bay}

A SPATT disc made of Diaion HP-20 resin was deployed in Mc Swynes Bay - Bruckless, NW Ireland $\left[54^{\circ} 36^{\prime} 47.98^{\prime \prime} \mathrm{N}, 8^{\circ} 23^{\prime} 31.99^{\prime \prime} \mathrm{W}\right]$. The SPATT disc was immersed from the $8^{\text {th }}$ until the $15^{\text {th }}$ of November 2005 at 5 meters depth.

\subsubsection{Galway Bay}

SPATT discs were placed at a single location in outer Galway Bay [53 $16^{\circ} 10.10^{\prime \prime} \mathrm{N}, 8^{\circ} 56^{\prime} 4.33^{\prime \prime}$ W] from the $17^{\text {th }}$ until the $31^{\text {st }}$ of August 2006. The sampling system consisted of three replicates of SPATT made of the five resin type (15 SPATTs) at two depths, one and five meters. The SPATTs were replaced after one-week exposure.

\subsection{LC-MS systems}

Three LC-MS systems were used for quantitation of toxins. Analyses performed in Ifremer were carried out on an ion trap LCQ instruments. Analyses performed at the Marine Institute were carried out on a Q-TOF Ultima for samples that contain OA and DTX1 and on a triple quadrupole (QqQ) Quattro Ultima for samples additionally containing toxins other than OA and DTX1.

\subsubsection{Analyses using Q-TOF}

Analyses for the study of the elution profiles of OA and DTX1 from the polymeric resins were performed using a HPLC Acquity system (Waters Corp., Manchester, UK) coupled to a Q-TOF Ultima (Micromass Ltd., Manchester, UK) equipped with a z-spray ESI source. Separation was achieved in isocratic elution for 8 min with 53\% phase A (100\% aqueous) and $47 \%$ phase B (95\% aqueous ACN), both containing $2 \mathrm{mM}$ ammonium formate. The flow rate was set at $0.25 \mathrm{ml} / \mathrm{min}$ and $5 \mu \mathrm{l}$ of samples were injected on a C8 BDS Hypersil $(50 \times 2 \mathrm{~mm}, 3 \mu \mathrm{m}$ particle size, guard column, $10 \times 2$ $\mathrm{mm}, 3 \mu \mathrm{m}$ ) column maintained at $25^{\circ} \mathrm{C}$. The Q-TOF was used in TOF-MS/MS mode, where the molecular ion is isolated in the quadrupole and where after collision in the collision cell, the whole fragmentation spectrum is obtained in the TOF. DTX1 was quantified using OA calibration as no DTX1 certified calibration solution was commercially available at the time of the study.

\subsubsection{Analyses using Quattro Ultima}

The resins used in SPATT discs deployed in Bruckless Bay and Galway Bay as well as the extracts of the SPATTs exposed to the $P$. lima culture for adsorption rate determination were analysed using a 2695 Waters HPLC coupled to a QqQ Quattro Ultima (Micromass Ltd., Manchester, UK) also equipped with a z-spray ESI source. Separation was achieved using a gradient elution using binary mobile phases at $0.25 \mathrm{ml} / \mathrm{min}$ on a C8 BDS Hypersil column $(50 \times 2 \mathrm{~mm}, 3 \mu \mathrm{m}$ particle size, guard column, $10 \times 2 \mathrm{~mm}, 3 \mu \mathrm{m}$ ). Mobile phase A consisted of $100 \%$ aqueous while B was $95 \%$ ACN. Both mobile phases contained $2 \mathrm{mM}$ ammonium formate and $50 \mathrm{mM}$ formic acid. The gradient started with $30 \% \mathrm{~B}$ at time zero linearly rising to $90 \% \mathrm{~B}$ at $8 \mathrm{~min}$. Then, $90 \%$ B was held for $0.5 \mathrm{~min}$, decreased to $30 \%$ B over 0.5 min which was held again for 5 min until the next run. The flow was diverted to the waste for the first $5 \mathrm{~min}$ of the analysis. The column temperature was set at $25^{\circ} \mathrm{C}$ and the injection volume at $5 \mu \mathrm{l}$. The Quattro Ultima was operated in multiple reaction-monitoring (MRM) mode, analysing two fragment ions per compound. Monitored transitions were as follows (precursor > fragment): $\quad$ OA $803.5>255.5$ and $803.5>803.5 ;$ DTX2 803.5 $>255.5$ and 803.5>803.5; DTX1 817.5>255.5 and 817.5>817.5;; PTX2 876.5>823.5; AZA1 842.5>654.4 and 842.5>672.4; AZA2 856.5>654.4 and 856.5>672.4; AZA3 828.5>640.4 and 828.5>658.4. OA and DTXs were analysed in negative ionisation mode while PTX2 and AZAs were analysed in positive ionization mode. AZA2 and AZA3 were quantified using AZA1 calibration as no certified calibration solutions of these compounds were commercially available at the time of the study.

\subsubsection{Analyses using LCQ}

Culture extracts obtained by method $C$ were analysed on a LCQ ion trap MS (Finnigan MAT, San Jose, US) with an ESI source. Separation was achieved with a Spectra system HPLC equipped with a Kromasil C18 column $(250 \times 2.0 \mathrm{~mm}, 5 \mu \mathrm{m}$ particle size $)$ at $40^{\circ} \mathrm{C}$. Isocratic elution was carried out using a mobile phase ACN/water (75:25) containing $0.1 \%$ TFA. The flow rate was set at $0.2 \mathrm{ml} / \mathrm{min}$ 
and the injection volume was $5 \mu$ l. Multiple tandem MS produced collision-induced dissociation (CID) spectra and were obtained using the protonated molecule for each toxin which fragmented similarly giving major ions due to the sequential loss of water molecules. OA and DTX1 were determined in posititve ionisation mode and using $\mathrm{MS}^{3}$ methods with the following target precursor and fragment ion combinations in the mass spectrometer: $\mathrm{MS}^{3}$ method OA $(\mathrm{m} / \mathrm{z} 787.0>769.1>751.0)$; $\mathrm{MS}^{3}$ method DTX1 $(\mathrm{m} / z \mathrm{z} 01.0>783.1>765.1)$. DTX1 was quantified using OA calibration as no DTX1 certified calibration solution was commercially available at the time of the study.

\subsection{Statistical evaluation}

Statistical calculations were carried out using Sigmastat 3.0. The significance test used to discriminate between the toxin adsorption capabilities of the polymeric resins was the two-way analysis of variance Holm-Sidak test.

\section{Results}

\subsection{Toxin desorption from naturally and artificially contaminated resins}

The elution profiles of OA and DTX1 determined for each polymeric resin using methanol at $1 \mathrm{ml} / \mathrm{min}$ are shown in Figure $1 A$ and $B$ respectively. The elution of OA and DTX1 from the HP-20, SP825L and XAD4 resins have a similar profile with a Gaussian type peak where the desorption reaches a maximum after elution with $5-7 \mathrm{ml}$ of methanol. The desorptions of OA and DTX1 from the SP850 and the L-493 did not follow that trend, as the first fraction was in both cases the most concentrated one. Excellent recoveries were obtained for the five resins using an elution with $23 \mathrm{ml}$ of methanol, ranging from 96 to $99 \%$ for both OA and DTX1 (calculated relatively to the amount of toxin recovered using $60 \mathrm{ml}$ of methanol), as shown in Table 2. Similarly, the same experiment has been carried out using the HP-20 resin from a naturally contaminated SPATT that was deployed in Bruckless for one week. OA, DTX2, PTX2, AZA1, -2 and -3 were found at quantifiable levels. The recoveries obtained using a $23 \mathrm{ml}$ elution with methanol (calculated relatively to the total amount recovered using $60 \mathrm{ml}$ ) ranged from 85 to $100 \%$ recoveries. The lowest recovery was obtained for AZA3 while the highest was obtained for DTX2 as shown in Table 3. The elution profile obtained for these toxins is shown in Figure $1 \mathrm{C}$, where the $\mathrm{Y}$-axis was normalised to the highest OA concentration found. Figure 1D shows the OA desorption profiles obtained using the naturally contaminated HP-20 resin exposed in Bruckless and the artificially contaminated HP20 resin immersed in lysed $P$. lima culture for four days. The elution profile from the naturally contaminated HP-20 shows that after elution with $23 \mathrm{ml}$ of methanol, OA could still be quantified in the extracts but only accounted for $2 \%$ of the total amount that was recovered using $60 \mathrm{ml}$.

\subsection{Toxicity $P$. lima culture}

The toxicities of the $P$. lima cultures were determined from the sum of intracellular and extracellular toxin content; the results are shown in Table 4. The concentration of free OA determined by LLE was $79.1 \pm 1.3 \mathrm{ng} / \mathrm{ml}$ (Method B) while the concentration obtained by SPE was $63.8 \pm 4.9 \mathrm{ng} / \mathrm{ml}$ (Method C). The quantification of the sum of free OA and OA ester derivatives determined by LLE combined to hydrolysis using $\mathrm{NaOH}$ (Method A) resulted in concentration of $125.2 \pm 9.6 \mathrm{ng} / \mathrm{ml}$ against $101.3 \pm 1.4$ $\mathrm{ng} / \mathrm{ml}$ determined by the SPE method and freeze-thaw technique (Method C). These results were in good agreement since both the hydrolysis procedure and the LC-MS methods and instruments were different. Furthermore, the concentration of free OA accounted for $63.2 \%$ and $63.0 \%$ of the sum of the concentrations of free OA and OA ester derivatives using LLE and SPE, respectively. The concentration of free DTX1 determined by LLE was $126.5 \pm 4.6 \mathrm{ng} / \mathrm{ml}$ and $99.7 \pm 11.6 \mathrm{ng} / \mathrm{ml}$ by SPE. DTX1 ester derivatives were not detected in any extract. The sum of the concentrations of free DTX1 and DTX1 ester derivatives obtained by method A was lower than the free DTX1 concentration obtained by method B. This suggests either DTX1 degradation during the hydrolysis process or signal suppression in the ESI source due to the presence of sodium chloride in the extract, as salts may cause signal suppression in LC-MS analysis. Sodium chloride is present as $\mathrm{HCl}$ is added to neutralise the extract hydrolysed by $\mathrm{NaOH}$. The concentrations obtained for free DTX1 and the sum of free DTX1 and DTX1 ester derivatives using method C were within the margin of errors. 


\subsection{Toxin accumulation in polymeric resins from $\boldsymbol{P}$. lima culture}

The average amount, calculated from three replicates, of OA and DTX1 accumulated on each resin at 12, 24, 48 and 72 hours is shown in Table 5 and Table 6 respectively. All resins were able to accumulate $\mathrm{OA}$ and DTX1 following a 12 hours exposure to the $P$. lima culture. The ratios of the amount of OA and DTX1 adsorbed on each resin were all between 1.20 and 1.25 apart for XAD4 where the ratio found was 1.05. The adsorption profiles of OA and DTX1 onto each resin is shown in Figure $2 \mathrm{~A}$ and $2 \mathrm{~B}$ respectively. The percentage of adsorption was calculated from the amount of $\mathrm{OA}$ and DTX1 found in the SPATTs and the amount of free OA and DTX1 found in the culture medium, given in Table 4. SP825L and SP850 were found to be the resins that adsorbed OA and DTX1 the most rapidly up to 48 hours. The HP-20 was the only resin that accumulated OA and DTX1 linearly up to $72 \mathrm{~h}$, correlation coefficients obtained for OA and DTX1 were 0.9819 and 0.9955 respectively. After 72 hours exposure, the HP-20 resin accumulated the largest amount of OA and DTX1 compared to the other resins assessed, reaching 24 and $12 \%$ of the free OA and DTX1 contained in the cells and in the culture media. However, the Holm-Sidak two way analysis of variance using contact time and polymeric resin type as the variable factors showed that there are no statistical differences between the OA adsorption rate obtained with the HP-20, the SP825L and the SP850 resins, and with the L493 and XAD4 resins. Furthermore, the same statistical test showed that L-493, SP825L, SP850 and XAD4 resins adsorbed equivalent amounts of OA following a 48 hours contact time and following a 72 hours contact time, suggesting that equilibrium was reached. The results obtained for DTX1 adsorption (Figure 2A) were in accordance with the OA results except for XAD4 that demonstrated similar adsorption rate towards DTX1 with the HP-20, the SP825L and the SP850 resins. No statistical differences were observed between HP-20, SP825L, SP850 and XAD4 resin types for DTX1 adsorption rate and similarly to the OA results, the SP825L, SP850 and XAD4 resins adsorbed equivalent amounts of DTX1 following 48 and 72 hours contact time.

\subsection{Toxin accumulation in polymeric resins from West Coast of Ireland}

The concentrations of OA obtained from the naturally contaminated SPATT discs made of the five selected polymeric resins are shown in Figure 3. It was found that HP-20 always accumulated a significantly greater amount of $O A$ than the other resins. No significant differences were observed in the amount of OA adsorbed onto the SP825L and SP850. The amount of OA accumulated on the L493 resin was lower than the previously mentioned resin. Finally, the XAD4 had extremely poor performances in the natural media as OA was barely quantifiable in the extracts. In addition to OA, the resins also accumulated quantifiable amounts of DTX2 as shown in Table 7. DTX2 was only quantifiable using the HP-20, the SP825L and the SP850. Furthermore, all resins also accumulated AZA1 at detection levels as well as relatively high amounts of PTX2 which were not quantified (data not shown).

\section{Discussion}

The SPATT technique is an attractive tool for the study of the distribution of lipophilic toxins at sea, as it presents a number of advantages over the current monitoring tools. The accumulation of the parent toxins avoiding bio-transformation that occur in shellfish such as the esterification of okadaic acid into 7-O-acyl Okadaic ester (Suzuki et al., 1999), the conversion of PTX2 into PTX2 seco-acid (Suzuki et al., 2001; Miles et al., 2004) and PTX2 seco-acid ester derivatives (Wilkins et al., 2006). Similarly, the oxidation of YTX into 45-hydroxy-YTX and carboxy-YTX (Aasen et al., 2005) can be avoided, thereby reducing the number of analytes to be considered in the analytical procedure. Moreover, it is often difficult to evaluate the toxicity of harmful algae bloom by cell identification and quantification in the water column. This is especially true for P. lima due to its epiphytic behaviour (Foden et al., 2005) and to the high variation in cell toxicities depending on their strains (Bravo et al., 2001). The SPATT technique is well suited to link cell populations and their densities to qualitative and quantitative data on their toxin production. In addition, the SPATT technique could be beneficial for the monitoring of AZAs as the organism responsible for the production of these toxins, initially reported as Protoperidinium crassipes (James et al., 2003), has still not been unambiguously identified. (Hess et al., 2005, Aasen et al., 2006).

The comparison of toxin desorption behaviours from the five polymeric resins was carried out by exposing the SPATTs to a lysed culture of $P$. lima where the resins were competing with each other for the accumulation of OA and DTX1. This approach was initially taken as an artificial contamination 
step, in order to load similar amounts of toxins on the five resins for subsequent desorption profile determination. The latter was achieved using preparative chromatography equipment in order to ensure good reproducibility in the methanol flow rate and in the volumes of fractions collected. The desorption profiles shown in Figure $1 \mathrm{~A}$ and Figure $1 \mathrm{~B}$ demonstrate the applicability of the elution method for the desorption of OA and DTX1 toxins from all resins selected for assessment. Furthermore, when the desorption profile relative to the most concentrated fraction in OA obtained from naturally contaminated SPATT (made of HP-20) is plotted with the desorption profile from SPATT (also made of HP-20) contaminated in artificial P. lima culture (Figure 1D) it is clear that both contamination processes led to similar desorption profile. The use of naturally contaminated SPATT from Bruckless, Ireland, allowed determination of the desorption profiles for AZA1, -2, -3, PTX2, OA and DTX2 as shown in Figure 1C. The data shown in Table 3 demonstrate the efficiency of the elution method for lipophilic toxin analysis as the recoveries obtained for OA, DTX2 and PTX2 were 98, 100 and $96 \%$ respectively. Lower recoveries were obtained for AZA3, -2 and -1 with 85, 91 and $93 \%$ respectively, probably due to the higher lipophilicity of these compounds. It must be emphasised that, from previous experiments carried out in Bruckless using the SPATT samplers for several weeks, it was observed that AZA3 is usually found in low concentrations compared to AZA1 and -2 (Fux et al., manuscript in preparation).

Applications of styrene DVB copolymer resin in aqueous environment requires a pre-wetting step because of the high hydrophobicity of the resins due to their highly aromatic surfaces. The wetting or activation process consists in the immersion of the resin in a water-soluble solvent such as methanol or acetone to displace the air from the pores, followed by immersion in water to displace the solvent by water molecules. Hence, care must be taken to ensure that the resins are kept moist until deployment at sea. Recent research in polymeric materials have shown that the wetting step of the polymeric resin XAD4 can be avoided by carrying out a Friedel and Crafts acylation on the styrene DVB resin structure ( $\mathrm{Li}$ et al., 2001). The introduction of a similar acylation step on the resins used for the preparation of SPATTs could offer more flexibility in deployment and storage.

Previous studies demonstrated that $P$. lima (PL2V) has a growth rate of 0.1 to 0.3 divisions/day, which would allow cultures to be in the late log phase after 30 days (Rausch de Traubenberg and Morlaix, 1995).Thus, the comparison of the five polymeric resins for their ability to accumulate OA and DTX1 from $P$. lima culture was carried out in a 2-month-old culture in order to ensure that significant variation in toxin concentration in the culture medium would not occur over the $72 \mathrm{~h}$ study period. Adsorption of OA and DTX1 on the HP-20 resin rose linearly up to $72 \mathrm{~h}$ while the other four resins seem to have reached saturation more rapidly. The results obtained for the HP-20 are in agreement with field trials carried out by MacKenzie et al. (2004) where the resin has been shown to accumulate toxins linearly up to at least 5 days.

This may be due to the larger pore size of the HP-20 and could be explained when looking at the diffusion pathways. Two types of diffusion must be considered, film diffusion and internal diffusion, which are due to the migration of molecules from the solution to the surface of the particles and to the migration from the surface to the interior of the particles, respectively. A simplified model of the adsorption mechanism is proposed in Figure 4Erreur! Source du renvoi introuvable.. Both phenomena are affected by the particle sizes, since the use of smaller particle size increases the surface area for film diffusion, and reduces the internal volume through which the molecule must diffuse. Therefore, the larger the particle sizes, the longer the time to reach equilibrium. Nevertheless, differences in adsorption rate were observed in this study despite the use of polymeric resin with similar particle size ranges given by the manufacturer (Table 1 ). The HP-20 was the only resin to adsorb a significantly higher amount of toxin between 48 and 72 hours when exposed to live culture and adsorbed the greater amount of toxins during the field trials suggesting that the pore size of the resin may govern the capacity and equilibration rate of toxin adsorption. Since the HP-20 had the smallest surface area and yet showed good performances for toxin adsorption, the adsorption rate does not seem to be dependant on the surface area.

The HP-20 adsorbed $24 \%$ of OA and $12 \%$ of DTX1 from the culture. The difference in concentration adsorbed may be related to their different excretion pathways and the different amounts of free toxin available for adsorption from the aqueous media. Studies on the production of OA and DTX1 in P. lima cultures over a 90 day period showed that $O A$ is either solely or partially produced from enzymatic hydrolysis of DTX4 (Quilliam et al., 1996). This was suggested following the discovery of high intracellular DTX4 concentration with only low concentrations of OA and DTX1 in boiled extracts, where enzymatic activity was stopped. Since OA was found to be the predominant toxin in the culture medium, followed by DTX1 and DTX4 in trace amounts, it was suggested that OA could be produced in the cell in low amount similar to DTX1, and that the majority of OA found in the medium is the result of a very fast enzymatic hydrolysis into OA diol ester derivatives, which are further hydrolysed at a 
lower rate to yield $\mathrm{OA}$. Studies on $P$. lima cell cycle and their related toxin production showed that DTX4 and OA/DTX1 are produced at different phases of the cell cycle (Pan et al., 1999). The same study reported that DTX4, OA, DTX1 and OA diol esters accounted for 54, 30, 12 and $4 \%$ of the total intracellular toxin content respectively, while only OA and trace amounts of DTX1 were detected in the culture medium. However, this study did not provide any evidence of OA being directly produced by the cell and as of yet, there is no study to the author's knowledge that demonstrated the potential production of free OA from $P$. lima cells. DTX1 production is not believed to occur through the same mechanism as there is no evidence of DTX1 derivatives being produced in P. lima cultures (Quilliam et al., 1996; Bravo et al., 2001; Nascimento et al., 2005).

The results obtained from the SPATTs immersed in Galway Bay are consistent with the above findings. The HP-20 resin has shown the ability to accumulate a significantly larger amount of OA than the other evaluated resins. The data from this study show that L-493 and XAD4 resins are not suitable to be used as receiving phase in passive samplers.

This study reported an efficient extraction method suitable for OA, DTX1, DTX2, AZA1, -2, -3 and PTX2 desorption from styrene-DVB polymeric resin. The comparison of several polymeric resins for toxin adsorption demonstrated that the use of the initially reported HP-20 resin as SPATT receiving phase remains the resin of choice for this application since field trial results showed a significantly greater amount of toxin being adsorbed on the HP-20 resin. Furthermore, this work presented evidences of significant toxin adsorption taking place on the assessed polymeric resins within $12 \mathrm{~h}$ of exposure in P. lima culture. This study re-iterates the potential application of the SPATT technology to rapidly obtain lipophilic toxin profiles and overcome some of the problems associated with the numerous shellfish metabolites.

\section{Acknowledgments}

The Marine Institute and BIOTOX (EU funded project 514074under FP6) have provided funds for this study. The authors also would like to thank Sophie Cardot for her assistance in the SPATT preparation.

\section{References}

Aasen, J., Samdal, I. A., Miles, C. O., Dahl, E., Briggs, L. R., and Aune, T., 2005. Yessotoxins in Norwegian blue mussels (Mytilus edulis): uptake from Protoceratium reticulatum, metabolism and depuration. Toxicon 45 (3), 265-272.

Aasen, J., Torgersen, T., Dahl, E., Naustvoll, L.J., Aune, T., 2006. Confirmation of azaspiracids in mussels in Norwegian coastal areas, and full profile at one location. In Proceedings of the 5th International Conference of Molluscan Shellfish Safety, 14-18 June 2004, Galway, Ireland, Molluscan Shellfish Safety, Deegan, B., Butler, C., Cusack, C., Henshilwood, K., Hess, P. Keaveney, S., McMahon, T., O'Cinneide, M., Lyons, D., Silke, J. (Eds.). ISBN: 1-902895-33-9, pp 162-169.

Bravo, I., Fernandez, M. L., Ramilo, I., and Martinez, A., 2001. Toxin composition of the toxic dinoflagellate Prorocentrum lima isolated from different locations along the Galician coast (NW Spain). Toxicon 39 (10), 1537-1545.

Foden, J., Purdie, D. A., Morris, S., and Nascimento, S., 2005. Epiphytic abundance and toxicity of Prorocentrum lima populations in the Fleet Lagoon, UK. Harmful Algae 4 (6 ), 1063-1074.

Guillard, R. and Ryther, J., 1962. Studies of marine planktonic diatoms. I. Cyclotella nana Hustedt and Detonula confervacea Cleve. Can. J. Microbiol. 8, 229-239.

Guillard, R., 1975. Culture of phytoplankton for feeding marine invertebrates. In Smith, W.L. and Chanle,y M.H. (eds.) Culture of Marine Invertebrate Animals, 22-60.

Hess, P., Nguyen, L., Aasen, J., Keogh, M., Kilcoyne, J., McCarron, P., and Aune, T., 2005. Tissue distribution, effects of cooking and parameters affecting the extraction of azaspiracids from mussels, Mytilus edulis, prior to analysis by liquid chromatography coupled to mass spectrometry. Toxicon 46 (1), 62-71.

Hess, P., McCarron, P., Rehmann, N., Kilcoyne, J., McMahon, T., Ryan, G., Ryan, M., Twiner, M., Doucette, G., Satake, M., Ito, E., Yasumoto, T., 2007. Isolation and purification of AZAs from naturally 
contaminated materials, and evaluation of their toxicological effects (ASTOX): in Marine Environment and Health series, 28, pp. IV + 121 - ISSN 16490053 - Web page (last accessed on 11/07/07): http://www.marine.ie/home/publicationsdata/publications/MEHS.htm

Hu, T., Marr, J., de Freitas, A. S. W., Quilliam, M. A., Walter, J. A., Wright, J. L. C., and Pleasance, S., 1992. New diol esters of okadaic acid isolated from cultures of the dinoflagellates Prorocentrum lima and Prorocentrum concavum. J. Nat. Prod. 55, 1631-7.

Hu, T., Curtis, J. M., Walter, J. A., and Wright, J. L. C., 1995. Identification of DTX-4, a new watersoluble phosphatase inhibitor from the toxic dinoflagellate Prorocentrum lima. J. Chem. Soc., Chem. Commun., 597-599.

James, K. J., Moroney, C., Roden, C., Satake, M., Yasumoto, T., Lehane, M., and Furey, A., 2003. Ubiquitous 'benign' alga emerges as the cause of shellfish contamination responsible for the human toxic syndrome, azaspiracid poisoning. Toxicon 41 (2), 145-151.

Kyriakopoulos, G., Doulia, D., and Anagnostopoulos, E., 2005. Adsorption of pesticides on porous polymeric adsorbents. Chemical Engineering Science 60 (4), 1177-1186.

Li, A., Zhang, Q., Chen, J., Fei, Z., Long, C., and Li, W., 2001. Adsorption of phenolic compounds on Amberlite XAD-4 and its acetylated derivative MX-4. Reactive and Functional Polymers 49 (3), 225233.

Li, A., Zhang, Q., Zhang, G., Chen, J., Fei, Z., and Liu, F., 2002. Adsorption of phenolic compounds from aqueous solutions by a water-compatible hypercrosslinked polymeric adsorbent. Chemosphere 47 (9), 981-989.

MacKenzie, L., Beuzenberg, V., Holland, P., McNabb, P., and Selwood, A., 2004. Solid phase adsorption toxin tracking (SPATT): a new monitoring tool that simulates the biotoxin contamination of filter feeding bivalves. Toxicon 44 (8), 901-918.

Miles, C. O., Wilkins, A. L., Munday, R., Dines, M. H., Hawkes, A. D., Briggs, L. R., Sandvik, M., Jensen, D. J., Cooney, J. M., and Holland, P. T., 2004. Isolation of pectenotoxin-2 from Dinophysis acuta and its conversion to pectenotoxin-2 seco acid, and preliminary assessment of their acute toxicities. Toxicon 43 (1), 1-9.

Nascimento, S. M., Purdie, D. A., and Morris, S., 2005. Morphology, toxin composition and pigment content of Prorocentrum lima strains isolated from a coastal lagoon in southern UK. Toxicon 45 (5), 633-649.

Otero, M., Zabkova, M., and Rodrigues, A. E., 2005. Comparative study of the adsorption of phenol and salicylic acid from aqueous solution onto nonionic polymeric resins. Separation and Purification Technology 45 (2), 86-95.

Pan, Y., Cembella, A. D., and Quilliam, M. A., 1999. Cell cycle and toxin production in the benthic dinoflagellate Prorocentrum lima. Marine Biology 134, 541-549.

Quilliam, M. A., Hardstaff, W. R., Ishida, N., McLachlan, J. L., Reeves, A. R., Ross, N. W., and Windust, A. J., 1996. Production of diarrhetic shellfish poisoning (DSP) toxins by Prorocentrum lima in culture and development of analytical methods. In: Yasumoto, Oshima Y, Fukuyo Y (eds) Harmful and Toxic algal blooms. IOC-UNESCO, Paris pp 289-292.

Rausch de Traubenberg, C. and Morlaix, M., 1995. Evidence of okadaic acid release into extracellular medium in cultures Prorocentrum lima (Ehrenberg) Dodge. In: Lassus, P., Arzul, G., Erard, E., Gentien, P. and Marcaillou, C., Editors, 1995. Harmful Marine Algal Blooms, Intercept Ltd, Lavoisier, pp. 493-498.Suzuki, T., Ota, H., and Yamasaki, M., 1999. Direct evidence of transformation of dinophysistoxin-1 to 7-O-acyl-dinophysistoxin-1 (dinophysistoxin-3) in the scallop Patinopecten yessoensis. Toxicon 37 (1), 187-198.

Suzuki, T., Mackenzie, L., Stirling, D., and Adamson, J., 2001. Pectenotoxin-2 seco acid: a toxin converted from pectenotoxin-2 by the New Zealand Greenshell mussel, Perna canaliculus. Toxicon 39 (4), 507-514.

Wilkins, A. L., Rehmann, N., Torgersen, T., Rundberget, T., Keogh, M., Petersen, D., Hess, P., Rise, F., and Miles, C. O., 2006. Identification of fatty acid esters of pectenotoxin-2 seco acid in blue mussels (Mytilus edulis) from Ireland. J Agric Food Chem 54 (15), 5672-5678.

Zhai, Z. C., Chen, J. L., Fei, Z. H., Wang, H. L., Li, A. M., and Zhang, Q. X., 2003. Adsorption of phenylhydrazine derivatives on hypercrosslinked polymeric adsorbents. Reactive and Functional Polymers 57 (2-3), 93-102. 
Table 1: Properties of selected polymeric resins

\begin{tabular}{llllll}
\hline & HP-20 & SP825 & SP850 & L-493 & XAD4 \\
\hline Density $[\mathrm{g} / \mathrm{L}]$ & 680 & 690 & 670 & 680 & 1020 \\
Pore volume $[\mathrm{mL} / \mathrm{g}]$ & 1.3 & 1.4 & 1.2 & 1.16 & 0.98 \\
Surface Area $\left[\mathrm{m}^{2} / \mathrm{g}\right]$ & 500 & 1000 & 1000 & 1100 & 725 \\
Pore radius $[\AA]$ & 200 & 57 & 38 & 46 & 40 \\
Particle size $[\mu \mathrm{m}]$ & $297-840$ & $250-840$ & $250-840$ & $297-840$ & $250-840$ \\
\hline
\end{tabular}

Table 2: Recoveries and concentrations of OA and DTX1 found in lysed $P$. lima culture. Amounts of toxins were obtained from LC-MS Q-TOF quantitation.

\begin{tabular}{|c|c|c|c|c|}
\hline & $\begin{array}{l}\text { Total amount of OA } \\
{[\mu \mathrm{g}]^{\text {a }}} \\
\sum_{12 \text { collected fractions }}\end{array}$ & $\begin{array}{l}\text { Recovery at } 23 \\
\mathrm{ml}\end{array}$ & $\begin{array}{l}\text { Total amount of DTX1 } \\
{[\mu \mathrm{g}]^{\mathrm{a}}} \\
\Sigma_{12 \text { collected fractions }}\end{array}$ & $\begin{array}{l}\text { Recovery at } 23 \\
\mathrm{ml}\end{array}$ \\
\hline HP-20 & 8.70 & $99 \%$ & 6.73 & $99 \%$ \\
\hline L-493 & 7.79 & $96 \%$ & 5.90 & $96 \%$ \\
\hline SP825L & 11.54 & $99 \%$ & 8.70 & $98 \%$ \\
\hline SP850 & 11.38 & $97 \%$ & 8.84 & $97 \%$ \\
\hline XAD4 & 7.28 & $98 \%$ & 5.36 & $98 \%$ \\
\hline
\end{tabular}

${ }^{a} 5 \mathrm{ml}$ fractions (+ $3 \mathrm{ml}$ dead volume) were collected and summed after individual analyses

Table 3: Recoveries obtained from SPATT discs naturally contaminated in Bruckless, North West of Ireland, $8^{\text {th }}$ to $15^{\text {th }}$ of November 2005. Amounts of toxins were obtained from triplicate injection on LCMS QqQ.

\begin{tabular}{lll}
\hline & Total Amount of toxin / ng & Recovery at $23 \mathrm{ml}$ \\
\hline OA & 874.4 & $98 \%$ \\
DTX2 & 268.7 & $100 \%$ \\
AZA1 & 740.5 & $93 \%$ \\
AZA2 & 219.9 & $91 \%$ \\
AZA3 & 52.3 & $85 \%$ \\
PTX2 & 738.1 & $98 \%$ \\
\hline
\end{tabular}


Table 4: Sum of intracellular and extracellular toxins of the $P$. lima culture determined by LLE combined to basic hydrolysis $(n=3)$ and by SPE combined to freeze-thaw technique $(n=3)$. Concentrations reported for LLE were obtained by triplicate injection on LC-MS Q- TOF and concentrations reported for SPE were obtained by triplicate injection on LC-MS ion trap.

\begin{tabular}{|c|c|c|c|c|}
\hline & & $\begin{array}{l}\text { OA ng/ml } \\
\text { of culture }\end{array}$ & $\begin{array}{l}\text { DTX1 ng/ml } \\
\text { of culture }\end{array}$ & Method \\
\hline & $\begin{array}{l}\text { Free toxin }+ \text { hydrophilic } \\
\text { derivatives } \\
\text { in } 30000 \text { cells } / \mathrm{ml} \text { culture }\end{array}$ & $125.2 \pm 9.6$ & $101.6 \pm 8.2$ & $A$ \\
\hline & $\begin{array}{l}\text { Free toxin } \\
\text { in } 30000 \text { cells } / \mathrm{ml} \text { culture }\end{array}$ & $79.1 \pm 1.3$ & $126.5 \pm 4.6$ & B \\
\hline Ш & $\begin{array}{l}\text { Hydrophilic toxin } \\
\text { derivatives } \\
\text { in } 30000 \text { cells } / \mathrm{ml} \text { culture }\end{array}$ & $18.0 \pm 0.8$ & $4.6 \pm 0.3$ & B \\
\hline & $\begin{array}{l}\text { Free toxin }+ \text { hydrophilic } \\
\text { derivatives } \\
\text { in } 30000 \text { cells } / \mathrm{ml} \text { culture }\end{array}$ & $101.3 \pm 1.4$ & $93.1 \pm 2.6$ & C \\
\hline & $\begin{array}{l}\text { Free toxin } \\
\text { in } 30000 \text { cells } / \mathrm{ml} \text { culture }\end{array}$ & $63.8 \pm 4.9$ & $99.7 \pm 11.6$ & C \\
\hline$\frac{w}{0}$ & $\begin{array}{l}\text { Hydrophilic toxin } \\
\text { derivatives } \\
\text { in } 30000 \text { cells } / \mathrm{ml} \text { culture }\end{array}$ & $37.5 \pm 6.3$ * & $<$ LOD * & C \\
\hline
\end{tabular}

* Calculated by difference between hydrolysed and non-hydrolysed extract

Table 5: Average OA concentration $(n=3)$ found in the five polymeric resins after immersion in $P$. lima culture for 12, 24, 48 and $72 \mathrm{~h}$. Quantitation was performed by duplicate injection on LC-MS Q-TOF.

\begin{tabular}{|c|c|c|c|c|c|}
\hline & & \multicolumn{4}{|c|}{$\begin{array}{l}\text { Average OA concentration in } n g / g \text { of resin }(n=3) \pm S D \text { found after } \\
\text { four exposure duration }\end{array}$} \\
\hline & & $12 \mathrm{~h}$ & $24 \mathrm{~h}$ & $48 \mathrm{~h}$ & $72 \mathrm{~h}$ \\
\hline & L-493 & $\begin{array}{l}267.4 \\
\pm 33.2\end{array}$ & $\begin{array}{l}498.8 \\
\pm 139.6\end{array}$ & $\begin{array}{l}779.3 \\
\pm 106.8\end{array}$ & $\begin{array}{l}973.8 \\
\pm 114.5\end{array}$ \\
\hline & HP-20 & $\begin{array}{l}418.5 \\
\pm 59.6\end{array}$ & $\begin{array}{l}585.5 \\
\pm 127.0\end{array}$ & $\begin{array}{l}982.2 \\
\pm 43.9\end{array}$ & $\begin{array}{l}1607.2 \\
\pm 238.3\end{array}$ \\
\hline & SP 825 & $\begin{array}{l}455.3 \\
\pm 42.0\end{array}$ & $\begin{array}{l}749.66 \\
\pm 8.5\end{array}$ & $\begin{array}{l}1275.9 \\
\pm 81.2\end{array}$ & $\begin{array}{l}1222.5 \\
\pm 124.8\end{array}$ \\
\hline & SP 850 & $\begin{array}{l}515.3 \\
\pm 89.6\end{array}$ & $\begin{array}{l}723.4 \\
\pm 255.1\end{array}$ & $\begin{array}{l}1072.5 \\
\pm 145.0\end{array}$ & $\begin{array}{l}1149.7 \\
\pm 134.0\end{array}$ \\
\hline 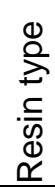 & XAD-4 & $\begin{array}{l}452.8 \\
\pm 9.9\end{array}$ & $\begin{array}{l}437.5 \\
\pm 98.8\end{array}$ & $\begin{array}{l}867.8 \\
\pm 158.0\end{array}$ & $\begin{array}{l}1061.7 \\
\pm 72.9\end{array}$ \\
\hline
\end{tabular}


Table 6: Average DTX1 concentration $(n=3)$ found in the five polymeric resins after immersion in $P$. lima culture for 12, 24, 48 and $72 \mathrm{~h}$. Quantitation was performed by duplicate injection on LC-MS QTOF.

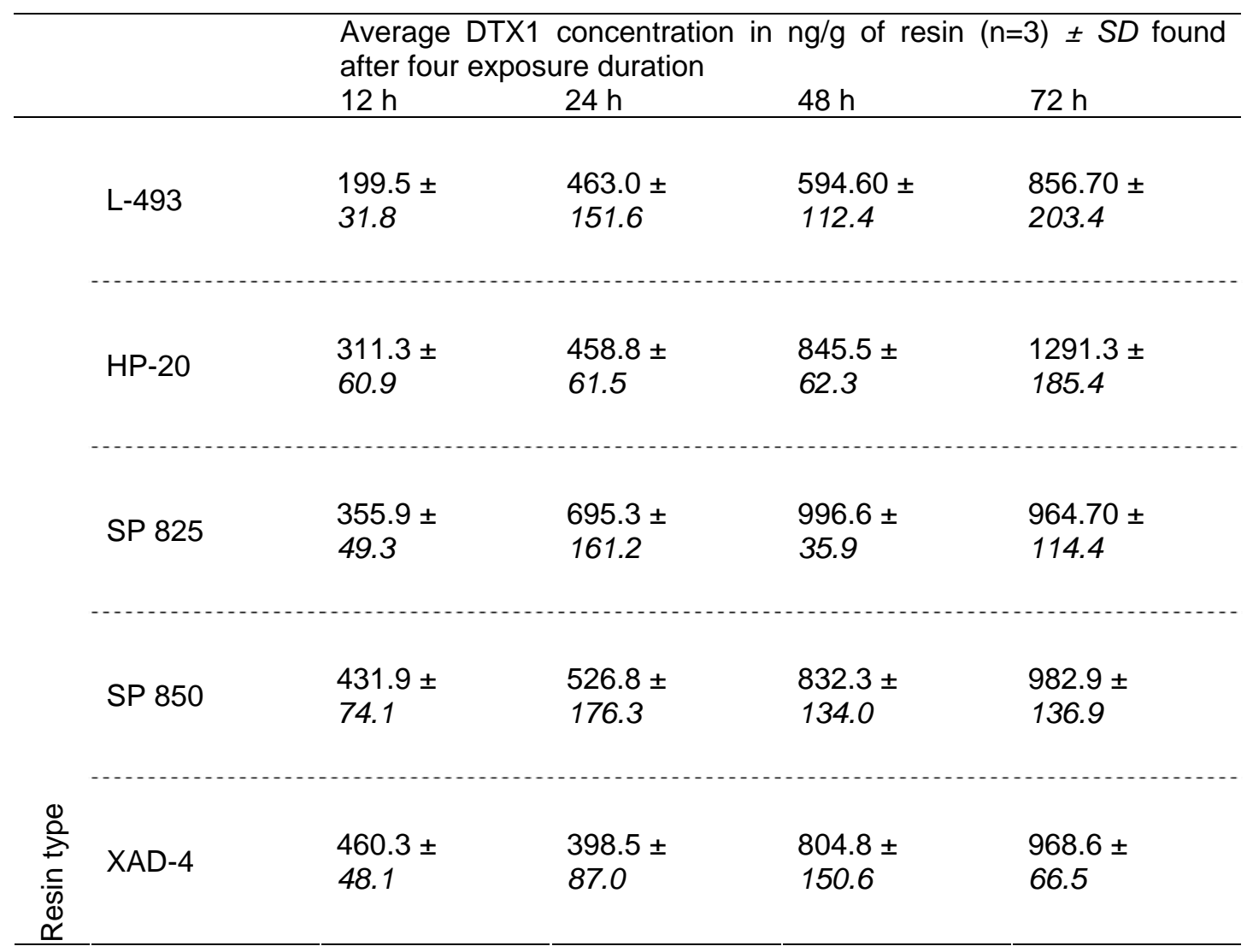

Table 7: DTX2 concentration ( $\mathrm{ng} / \mathrm{g}) \pm S D(\mathrm{n}=3)$ accumulated onto the five polymeric resins in Galway Bay - West Coast of Ireland. Quantitation was performed by triplicate injection on LC-MS QqQ.

\begin{tabular}{lllll}
\hline Retrieval Date & $24 / 08 / 06$ & & $31 / 08 / 06$ & \\
Sampling Depth & $1 \mathrm{~m}$ & $5 \mathrm{~m}$ & $1 \mathrm{~m}$ & $5 \mathrm{~m}$ \\
\hline L-493 [ng/g] & $<\mathrm{LOQ}$ & $<\mathrm{LOQ}$ & $<\mathrm{LOQ}$ & $<\mathrm{LOQ}$ \\
HP-20 [ng/g] & $46.4 \pm 8.3$ & $39.4 \pm 6.0$ & $49.3 \pm 4.5$ & $40.1 \pm 18.6$ \\
SP 825 [ng/g] & $33.3 \pm 6.1$ & $31.6 \pm 4.2$ & $<\mathrm{LOQ}$ & $46.8 \pm 3.4$ \\
SP 850 [ng/g] & $30.5 \pm 11.5$ & $20.2 \pm 1.6$ & $32.3 \pm 14.2$ & $27.8 \pm 9.9$ \\
XAD-4 [ng/g] & $<\mathrm{LOQ}$ & $<\mathrm{LOQ}$ & $<\mathrm{LOQ}$ & $<\mathrm{LOQ}$ \\
\hline
\end{tabular}




\section{Figures}

Figure 1: A) Elution profile of $O A$ from five polymeric resins immersed in a lysate $P$. lima culture. Quantitation was performed by LC-MS Q-TOF. B) Elution profile of DTX1 from five polymeric resins immersed in a lysate $P$. lima culture. Quantitation was performed by LC-MS Q-TOF. C) Elution profile of OA, DTX1, PTX2, AZA3, -2 and -1 from naturally contaminated SPATT disc. Quantitation was performed by LC-MS QqQ. D) Comparison of OA elution profile from naturally contaminated SPATT disc and SPATT bag contaminated in P. lima culture. Quantitation was performed by LC-MS Q-TOF. 

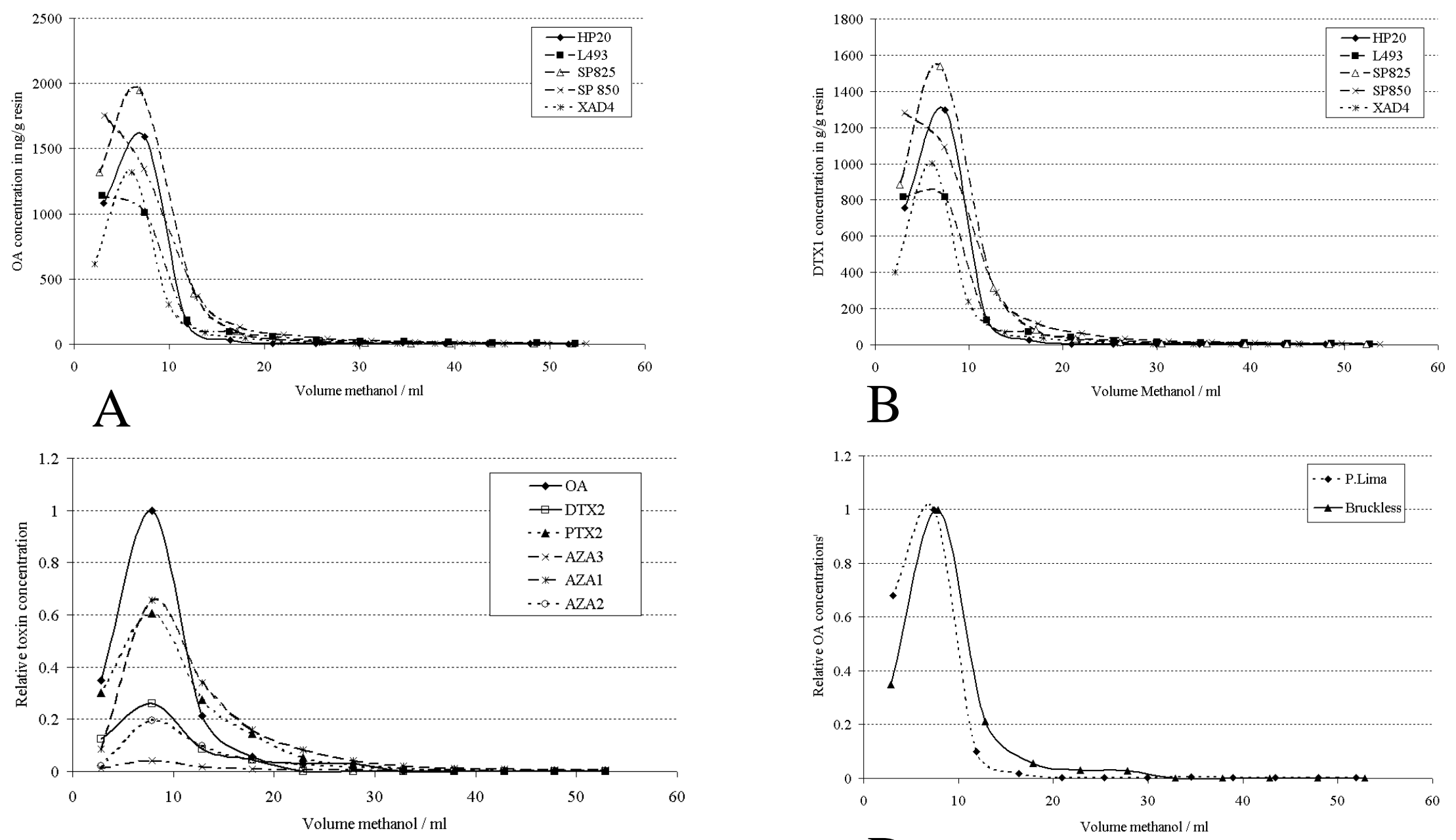

C

D 
Figure 2: A) Adsorption profiles of $O A$ on five polymeric resins from a culture of $P$. lima over 72 hours. B) Adsorption profiles of DTX1 on five polymeric resins from a culture of $P$. lima over 72 hours. Each point represents the average of three samples. Quantitation was performed by duplicate injection on LC-MS Q-TOF. 

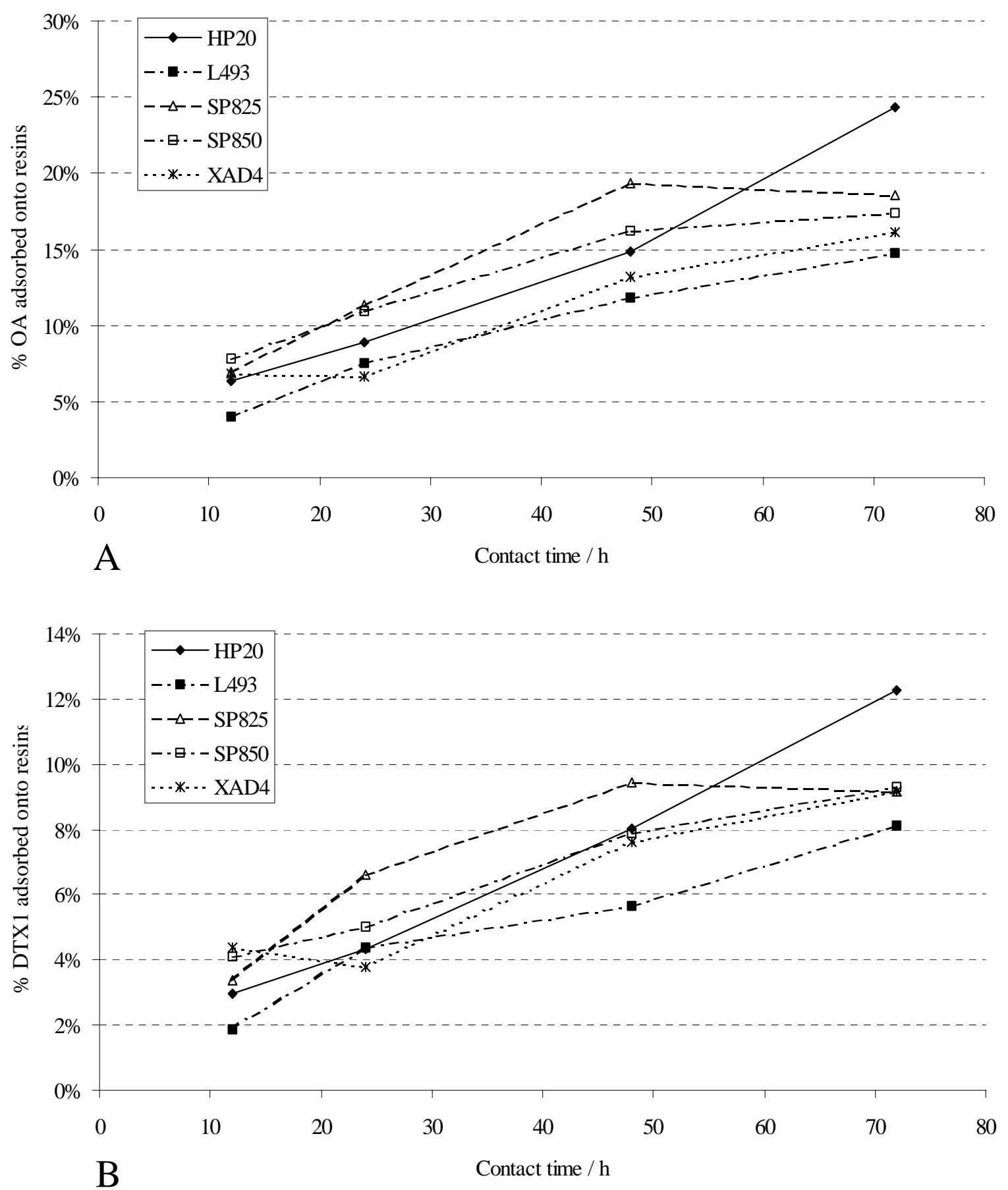
Figure 3: OA concentrations found in five polymeric resins immersed in Galway bay. Error bars represent the standard deviation obtained on three SPATT replicates. Quantitation was performed by triplicate injection on LC-MS QqQ. 


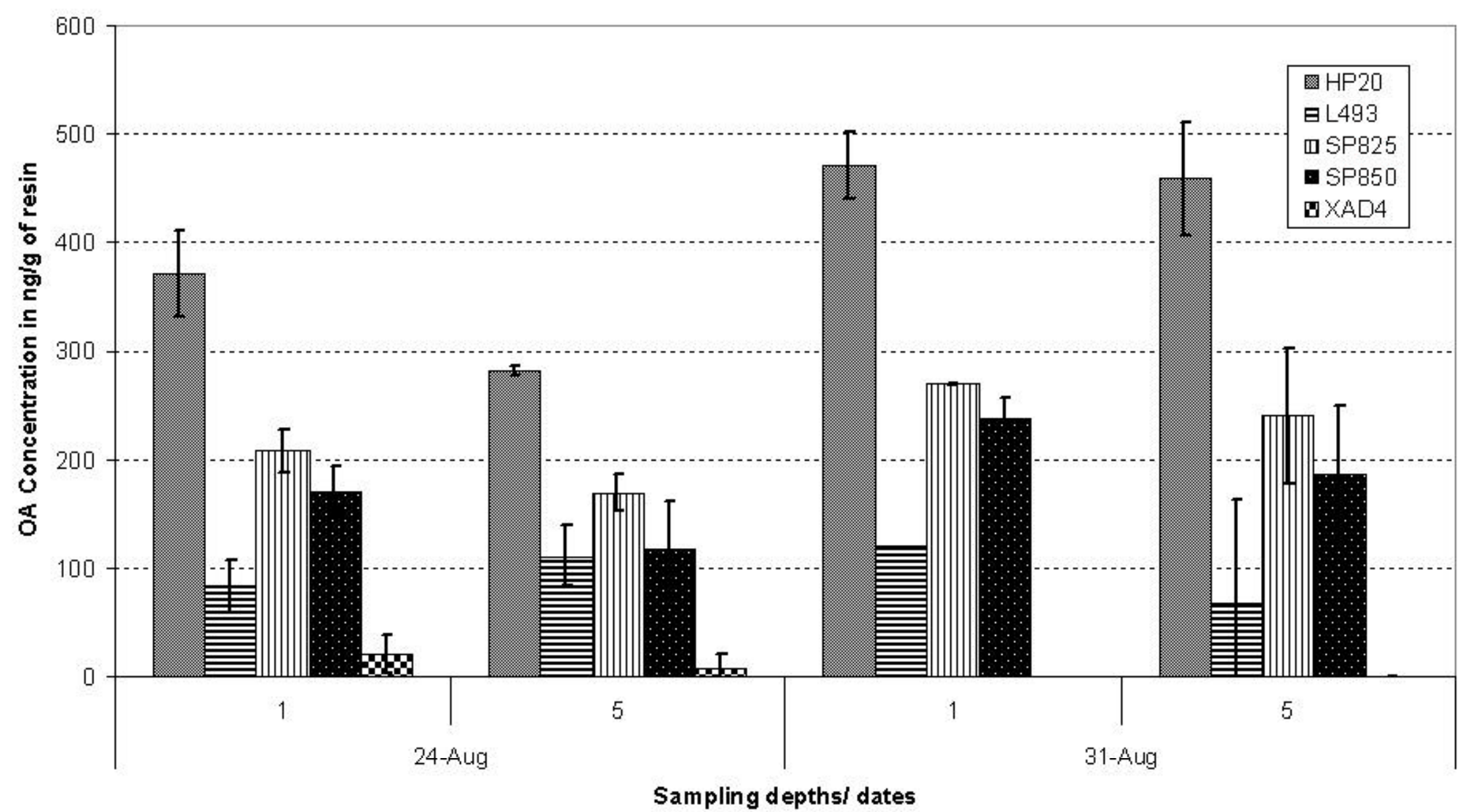


Figure 4 : Simplified model proposed for diffusion processes in macroreticular polymer particles. Film diffusion is shown by the migration of analyte from the solution to the surface of the particles. Internal diffusion is shown by migration of analyte from the surface to the interior of the particle. 

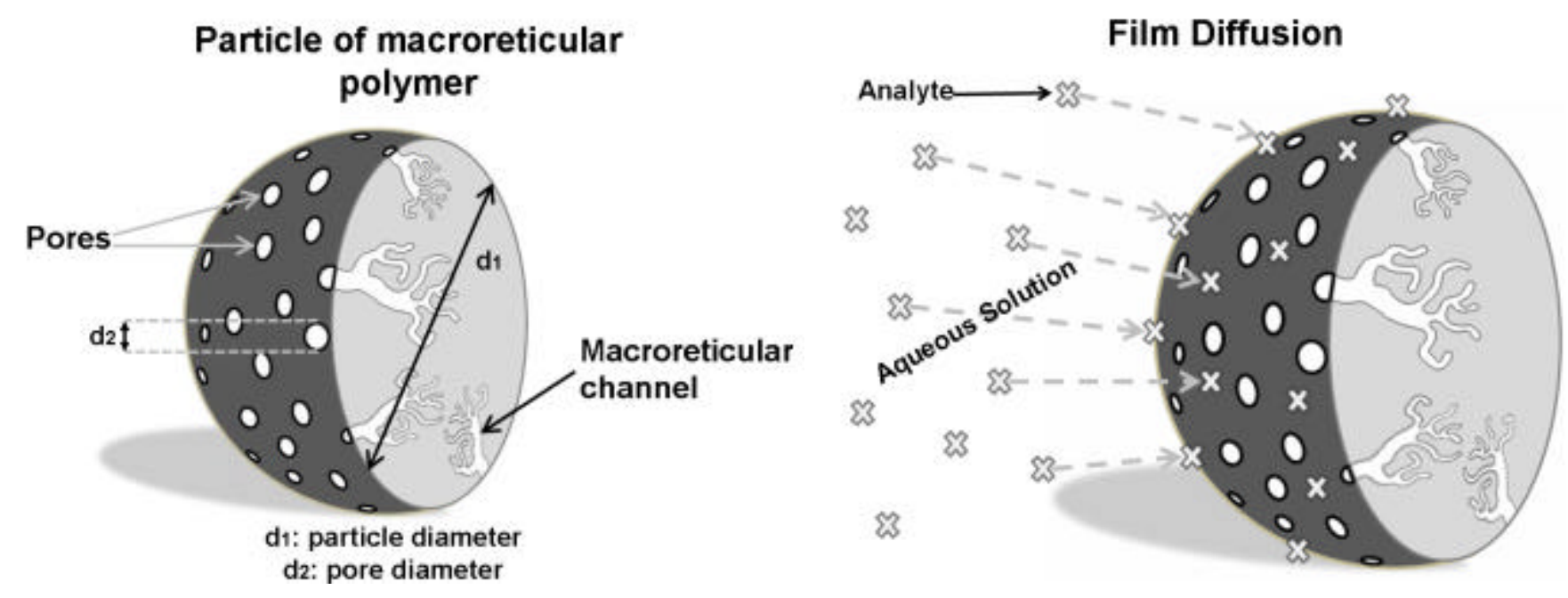

\section{Internal Diffusion}

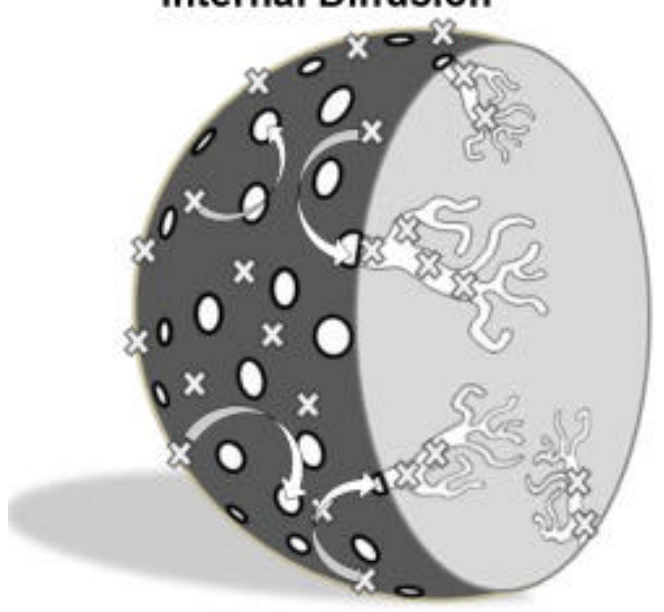

